\title{
The impact of COL1A1 and COL6A1 expression on hypospadias and penile curvature severity
}

\author{
Prahara Yuri ${ }^{*}$ (D) Gunadi ${ }^{2}$, Rahmadani Puji Lestari ${ }^{1}$, Firly Putri Fardilla ${ }^{1}$, Wiwit Ananda Wahyu Setyaningsih ${ }^{3}$, \\ Nur Arfian ${ }^{3}$ and Ishandono Dachlan ${ }^{4}$
}

\begin{abstract}
Background: Hypospadias, the most frequent congenital male external genitalia abnormality, is usually associated with curvature of the ventral penis, i.e. chordee. Abnormality of darto tissue has been suggested as the pathophysiology of chordees. Collagen is one of the most abundant fibrous proteins within the extracellular matrix. In this study, we determined the expression of collagen 1 (COL1A1) and COL6A1 in patients with hypospadias and associated them with the severity of penile curvature.

Methods: We included 60 children $<18$ years old, consisting of 20 distal hypospadias, 20 proximal hypospadias patients, and 20 controls in our institution from 2017 - 2020. The expression of COL1A1 and COL6A1 in darto tissue was determined by reverse-transcriptase polymerase chain reaction (qPCR). The penile curvature severity was classified as mild ( $<30$ degrees), moderate (30-60 degrees), and severe ( $>60$ degrees).

Results: qPCR showed that COLIA1 and COL6A1 expression was significantly downregulated in the distal (0.88 $(0.38-2.53)$ and $0.54(0.16-4.35)$, respectively) and proximal $0.76(0.33-2.57)$ and $0.57(0.18-1.38)$, respectively) hypospadias groups compared to controls (1.85 (0.24-4.61) and $0.93(0.17-4.06)$, respectively) with $p$-values of 0.024 and 0.018 , respectively. Furthermore, there was a moderate correlation between COL1A1 and COL6A1 expression $(r=0.458$, $p<0.0001)$. Interestingly, COL1A1 and COL6A1 were also significantly downregulated in the moderate and severe chordee groups compared to the mild chordee groups, with $p$-values of 0.003 and 0.037 , respectively.
\end{abstract}

Conclusions: Aberrant COLIA1 and COL6A1 expression might affect abnormalities in darto tissue and penile curvature severity in hypospadias patients.

Keywords: Chordee, COL1A1, COL6A1, Expressions, Hypospadias, Penile curvature severity, qPCR

\section{Background}

Hypospadias is the most frequent congenital penile anomaly that affects male external genitalia, with an incidence of approximately 1 in 250 male newborns. It is caused by tissue underdevelopment on the ventral aspect

\footnotetext{
*Correspondence: prahara.yuri@ugm.ac.id

${ }^{1}$ Division of Urology, Department of Surgery, Faculty of Medicine, Public Health and Nursing, Universitas Gadjah Mada/Dr. Sardjito Hospital, J. Kesehatan No.1, Yogyakarta 55281, Indonesia

Full list of author information is available at the end of the article
}

of the penis, resulting in an abnormal location of the urethral opening on the penile underside [1]. Elastosonography found deep alteration of hypospadias penile anatomy, in which the corpus spongiosum is stiffer and less elastic with less developed cavernous corpora [2].

Hypospadias is associated with curvature of the ventral penis, called the chordee. It is caused by the insufficiency or disorganization of the complex growth (the vascular and fascial structures) of the ventral penis [3]. Resection of dartos tissue usually straightens the penis in patients with chordee and buried penis, suggesting that 
the pathophysiology of these anomalies is related to dartos tissue [4].

The extracellular matrix (ECM) is a noncellular macromolecular network that supports cellular processes, such as proliferation, migration, differentiation, and homeostasis [5]. One of the most abundant fibrous proteins within the ECM is collagen. It has been considered the main component of the fibrous skeleton of the corpus cavernosum penis and is ubiquitous within the erectile tissues of the human penis $[6,7]$.

Fibrillar collagens are widely distributed in tissues providing tensile strength. Most fibrillar collagen is type 1 collagen, which can be found throughout the tissue beneath the urethral plate $[6,7]$. Type 6 collagen (COL6A1) binds to type 1 collagen (COL1A1) to form thicker collagen fibers. COL6A1 is a part of the beaded filament-forming collagens and the most studied member of its group [8]. The dartos fascia in hypospadias is an abnormal tissue, characterized by inelastic and thick tissue, but it is not the same with fibrotic tissue [9]. Therefore, we determined the expression of collagen 1 (COL1A1) and COL6A1 in patients with hypospadias and associated them with the severity of penile curvature.

\section{Methods}

We included 60 children $<18$ years old, consisting of 20 distal hypospadias, 20 proximal hypospadias patients, and 20 controls in our institution from 2017 - 2020 . Detailed history and thorough examination of patients with hypospadias were performed by one urologist. We harvested periurethral darto tissue during urethroplasty in hypospadias patients and circumcision in normal penis samples.

\section{Reverse-transcriptase polymerase chain reaction (qPCR) assays}

Fragments of the darto tissue were kept in RNAlater (Ambion, AM7021) solution before extraction. The tissue was extracted using Genezol RNA solution (GENE$\mathrm{zol}^{\mathrm{TM}}$, Cat. No. GZR100). cDNA was synthesized using an Excel RT Reverse Transcriptase Kit (RP1300, SMOBIO, Hsinchu City, Taiwan) with PCR conditions of $25^{\circ} \mathrm{C}$ for $10 \mathrm{~min}$ (denaturation), $42^{\circ} \mathrm{C}$ for $50 \mathrm{~min}$ (annealing), and $85^{\circ} \mathrm{C}$ for 5 min (extension).

qPCR was performed by mixing the cDNA and Taq Master Mix (GoTaq ${ }^{\circledR}$ Green Master Mix, Cat. M7122) with the following primer genes: COL1A1 (F: 5'-TAC AGCGTCACTGTCGATGGC- $3^{\prime}$ and R: 5'-TCAATC ACTGTCTTGCCCCAG-3'), COL6A1 (F: 5'-GACCTC GGACCTGTTGGGTAC- $3^{\prime}$ and R: $5^{\prime}$-TACCCCATC TCCCCCTTCAC-3') [10], and GAPDH (F: $5^{\prime}$-GCACCG TCAAGGCTGAGAAC- $3^{\prime}$ and R: $5^{\prime}$-TGGTGAAGACGC CAGTGGA-3') [11]. qPCR conditions were initiated with denaturation at $94{ }^{\circ} \mathrm{C}$ for $2 \mathrm{~min}$, followed by up to 40 cycles consisting of $94{ }^{\circ} \mathrm{C}$ for $10 \mathrm{~s}$, annealing at $54{ }^{\circ} \mathrm{C}$, $58{ }^{\circ} \mathrm{C}, 63{ }^{\circ} \mathrm{C}$ (COL6A1, COL1A1, and GAPDH, respectively) for $30 \mathrm{~s}$, and $72{ }^{\circ} \mathrm{C}$ for $1 \mathrm{~min}$, followed by a final extension at $72{ }^{\circ} \mathrm{C}$ for $10 \mathrm{~min}$. PCR products were then separated by $2 \%$ agarose gel along with a 100 -bp DNA ladder (Bioron, Germany, Cat. No. 306009) (Fig. 1). Gene expression was quantified using ImageJ software for densitometry analysis. (Fig. 2).

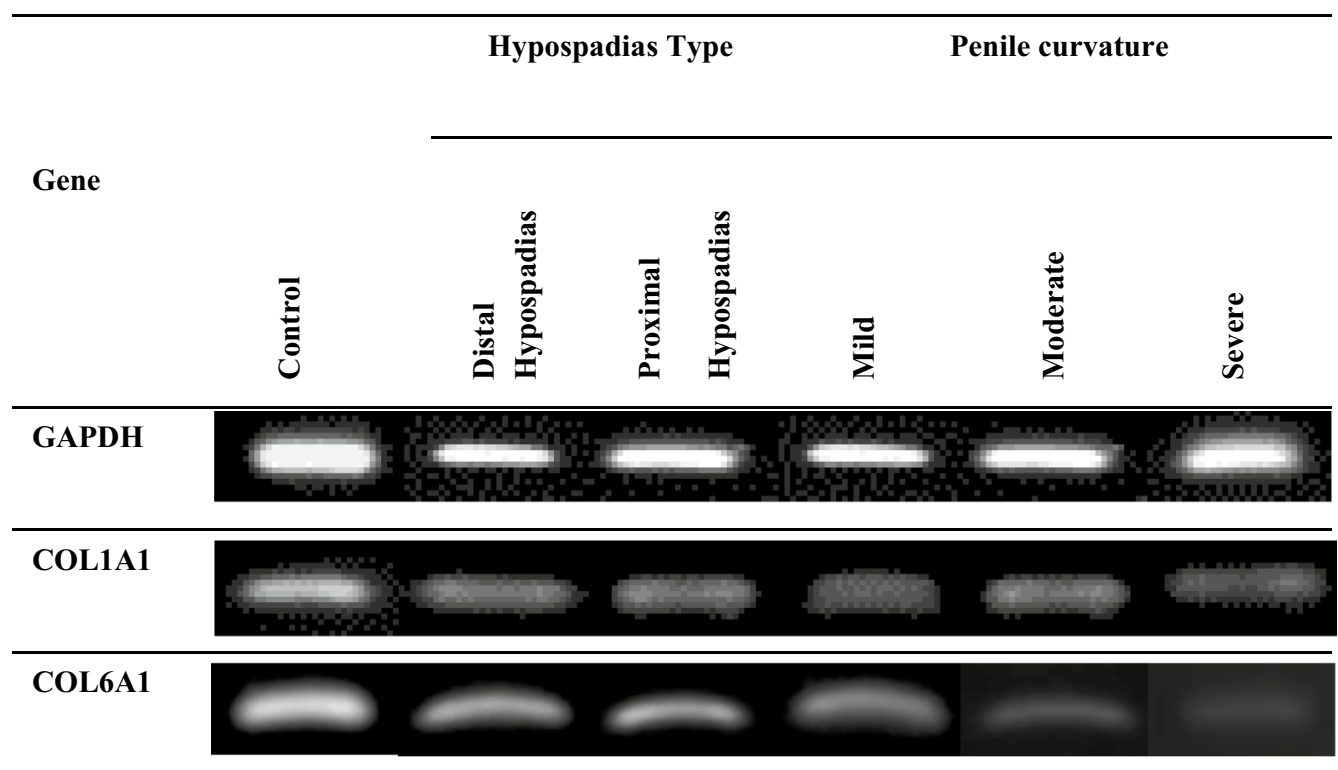

Fig. 1 Representative of qPCR products of COLIA1 and COL6A1. GAPDH was used as reference gene 


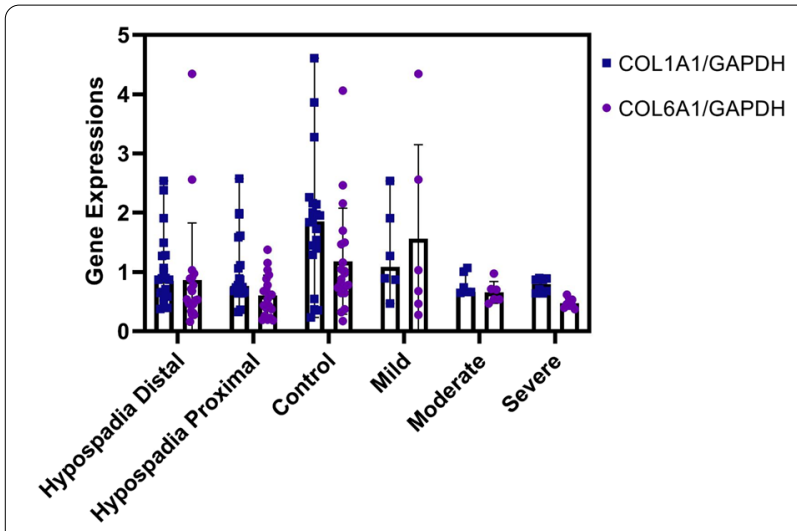

Fig. 2 The COLIA1 and COL6A1 gene expressions in hypospadias patients and controls and among hypospadias groups, moderate and severe penile curvature

\section{Statistical analysis}

Data were analyzed for their normality distribution using the Kolmogorov-Smirnov test. Kruskal-Wallis and Mann-Whitney U tests were used for the data that were not normally distributed, while the normally distributed data were analyzed with one-way ANOVA tests. $p<0.05$ was considered statistically significant.

\section{Results}

The baseline characteristics of our patients are described in Table 1. Most patients showed midshaft and penoscrotal hypospadias (67.5\%) (Table 1). qPCR showed that COL1A1 and COL6A1 expression was significantly downregulated in the distal $(0.88(0.38-2.53)$ and 0.54 (0.16-4.35), respectively) and proximal (0.76 (0.33$2.57)$ and 0.57 (0.18-1.38), respectively) hypospadias groups compared to controls (1.85 (0.24-4.61) and 0.93 (0.17-4.06), respectively) with $p$-values of 0.024 and 0.018 , respectively (Table 2 ). Interestingly, COL1A1 and COL6A1 were also significantly downregulated in the moderate and severe chordee groups compared to the mild chordee groups, with $p$-values of 0.003 and 0.037 , respectively (Table 2 ).

Moreover, there was no significant difference in COL1A1 and COL6A1 expression between proximal and distal hypospadias or severe and moderate penile curvature (Table 3 ). Furthermore, there was a moderate correlation between COL1A1 and COL6A1 expression $(r=0.458, p=0.000)$.

\section{Discussion}

Here, we are able to show downregulated COL1A1 and COL6A1 expression in hypospadias patients with moderate and severe penile curvature. These results are
Table 1 Characteristics of all patients in our institution

\begin{tabular}{|c|c|c|}
\hline Characteristics & Mean \pm SD; N (\%) & $P$ value \\
\hline \multicolumn{3}{|l|}{ Age (years) } \\
\hline $\begin{array}{l}\text { Hypospadias patients } \\
\text { Controls }\end{array}$ & $\begin{array}{l}7.85 \pm 3.9 \\
5.71 \pm 3.92\end{array}$ & 0.052 \\
\hline Hypospadias type $(n=40)$ & & $\mathrm{N} / \mathrm{A}$ \\
\hline \multicolumn{3}{|l|}{ Distal } \\
\hline Glandular & $1(2.5)$ & \\
\hline Subcoronal & $5(12.5)$ & \\
\hline Midshaft & $14(35)$ & \\
\hline \multicolumn{3}{|l|}{ Proximal } \\
\hline $\begin{array}{l}\text { Penoscrotal } \\
\text { Scrotal } \\
\text { Perineal }\end{array}$ & $\begin{array}{l}13(32.5) \\
6(15) \\
1(2.5)\end{array}$ & \\
\hline Penile curvature $(n=40)$ & & 0.132 \\
\hline $\begin{array}{l}\text { Mild (<30 degree) } \\
\text { Moderate (30-60degree) } \\
\text { Severe ( }>60 \text { degree) }\end{array}$ & $\begin{array}{l}14(35) \\
12(30) \\
14(35)\end{array}$ & \\
\hline \multicolumn{3}{|l|}{ Penoscrotal transposition } \\
\hline $\begin{array}{l}\text { Yes } \\
\text { No }\end{array}$ & $\begin{array}{l}2(5) \\
38(95)\end{array}$ & 0.147 \\
\hline \multicolumn{3}{|l|}{ Bifid scrotum } \\
\hline $\begin{array}{l}\text { Yes } \\
\text { No }\end{array}$ & $\begin{array}{l}6(15) \\
34(85)\end{array}$ & 0.376 \\
\hline
\end{tabular}

$S D$ standard deviation

Significant result $p<0.05$

consistent with previous research, which found that the mean number of total collagen fibers in dartos tissue in hypospadias was lower but had thicker fibers compared to normal patients [9]. They also found that the hypospadias tissue anomaly consisted of a thick and inelastic tissue, although it was not always followed by an increase in collagen [9]. Another study showed no evidence of fibrous bands or dysplastic tissue in subepithelial biopsies analyzed in 17 prepubertal boys undergoing hypospadias repair [12]. Eros et al. proposed no difference in collagen intensity between normal areas and under the urethral plate of patients with hypospadias [13].

Type 1 collagen is the most abundant collagen. It is the predominant component of interstitial membranes. It is also associated with fibrosis and fibrogenesis [14]. Hayashi et al. [6] revealed that during the maturation stage of scar formation, the collagen subtype I is produced excessively, developing the fibrils with large and stiff bands. This process might be associated with the less tumescence in the penis with fibrosis of the corpus cavernosum [6].

This paper also investigated the gene expression of COL6A1 as the most studied type of collagen in the beaded filament-forming collagen group. It plays a central role in cell attachments and connections between tissues and the surrounding matrix [15]. Type 6 collagen 
Table 2 Comparison of COL1A1 and COL6A1 expressions based on hypospadias type and penile curvature severity

\begin{tabular}{lllll}
\hline Hypospadias type & Distal Hypospadias & Proximal Hypospadias & Control & $P$-value \\
\hline COL1A1 & $0.88(0.38-2.53)$ & $0.76(0.33-2.57)$ & $1.85(0.24-4.61)$ & $0.024^{*}$ \\
COL6A1 & $0.54(0.16-4.35)$ & $0.57(0.18-1.38)$ & $0.93(0.17-4.06)$ & $0.018^{*}$ \\
Penile curvature Severity & Mild $(\mathrm{n}=14)$ & Moderate $(\mathrm{n}=12)$ & Severe $(\mathrm{n}=14)$ & $0.73(0.38-1.11)$ \\
COL1A1 & $1.56(0.47-2.57)$ & $0.69(0.33-1.59)$ & $0.44(0.18-0.89)$ & $0.003^{*}$ \\
COL6A1 & $0.90(0.16-4.35)$ & $0.57(0.23-1.04)$ & $0.037^{*}$ \\
\hline
\end{tabular}

* , significant result $p<0.05$ (Kruskal Wallis test)

Table 3 Comparison of COL1A1 and COL6A1 expressions between hypospadias groups, with moderate and severe penile curvature

\begin{tabular}{|c|c|c|c|c|c|c|c|c|c|c|}
\hline \multirow[t]{2}{*}{ Gene } & \multicolumn{2}{|c|}{ Hypospadias type } & \multirow[t]{2}{*}{$p$} & \multicolumn{2}{|c|}{$95 \% \mathrm{Cl}$} & \multirow{2}{*}{\multicolumn{2}{|c|}{ Penile Curvature }} & \multirow[t]{2}{*}{$p^{*}$} & \multicolumn{2}{|l|}{$95 \% \mathrm{Cl}$} \\
\hline & & & & Lower & Upper & & & & Lower & Upper \\
\hline COL1A1 & Distal & Proximal & 0.957 & 0.963 & 0.972 & Moderate & Severe & 0.877 & 0.896 & 0.911 \\
\hline COL6A1 & Distal & Proximal & 0.570 & 0.570 & 0.596 & Moderate & Severe & 0.123 & 0.125 & 0.142 \\
\hline
\end{tabular}

*Mann-Whitney test; $\mathrm{Cl}$, confidence interval; significant result $p<0.05$

also regulates fibrogenesis by modulating the interactions among cells. It stimulates the activation of mesenchymal cells into myofibroblasts, resulting in extracellular matrix deposition and tissue fibrosis [15]. In lung fibrosis, type 6 collagen is increasingly expressed [15]. However, this study found decreased gene expression of COL6A1 in the hypospadias group compared to the control group. This finding might be related to the downregulation of COL1A1, which was found in this paper, suggesting that type 6 collagen is bound together to the sides of type 1 collagen to form thicker collagen fibers [7]. We found a significant positive correlation between COL1A1 and COL6A1.

The etiology of chordee in hypospadias remains unclear. Resection of dartos tissue usually can straighten the penis in patients with chordee and buried penis, suggesting that the pathophysiology of these anomalies is related to dartos tissue [4]. The composition of Dartos fibromuscular tissue determines tissue elasticity and skin mobility $[4,12]$.

Collagen is a part of the tissue backbone. During tissue turnover, it is formed and degraded to maintain tissue health and homeostasis. Imbalance of that process leads to fibrosis. Fibrosis is known as excessive formation of connective tissue, which damages the structure and function of its tissue [16]. Chordee occurs because of fibrosis in darto tissue, which disrupts tissue elasticity and results in penis curving [17].

We also investigated the significant difference in COL1A1 and COL6A1 expression among groups based on penile curvature in the hypospadias group. Mostly, severe forms of hypospadias are related to a significant chordee and a urethral meatus located proximal to the midshaft of the penis [18]. Another study proposed that the severity of chordee is generally proportional to the degree of hypospadias [19]. Many factors, such as abnormal development of the urethral plate, fibrotic mesenchymal tissue at the urethral meatus, and ventral-dorsal corporal disproportion, may be interconnected, resulting in different degrees in the final severity of curvature in each patient [20]. The Dartos tissue pattern is not influenced by age. Race and genetics may affect penis development and need further investigation [4]. Finally, for clinical implications, one of the important steps before urethroplasty is the release of fibrous tissue. The urethral plate malformation might be not associated with the most penile curvature [6]. Therefore, leaving the urethral plate is preferred by most hypospadiologists [6]. In addition, removal of the tissue under the urethral plate is still debatable [6], while excision of the inelastic dartos tissue during reconstructive surgery is recommended [9].

\section{Conclusion}

Aberrant COL1A1 and COL6A1 expression might affect abnormalities in darto tissue and penile curvature severity in hypospadias patients.

\section{Abbreviation}

ECM: Extracellular matrix; COL1A1: Collagen 1 subtype alpha 1; COL6A1: Collagen 6 subtype alpha 1; GAPDH: Glyceraldehyde 3-phosphate dehydrogenase; GPCR: Reverse-transcriptase polymerase chain reaction; ECM: Extracellular matrix; COL1A1: Collagen 1 subtype alpha 1; COL6A1: Collagen 6 subtype 
alpha 1; GAPDH: Glyceraldehyde 3-phosphate dehydrogenase; qPCR: Reversetranscriptase polymerase chain reaction.

\section{Acknowledgements}

We thank all staff and nurses who took care of the patients.

\section{Authors' contributions}

PY collected the patient data, and PY, ID, and G analyzed and interpreted the data. PY, WAWS, NA, RPL, FPF performed PCR examination of the darto tissue. $P Y, I D$, and $G$ were a major contributor in writing the manuscript. All authors read and approved the final manuscript.

\section{Funding}

This work was supported by Rekognisi Tugas Akhir, Universitas Gadjah Mada (No: 2640/UN1/DITLIT/DIT-LIT/PT/2020 to G.). The funders had no role in the study design, data collection and analysis, decision to publish, or preparation of the manuscript.

\section{Availability of data and materials}

All data generated or analyzed during this study are included in the submission. The raw data can be requested to the corresponding author.

\section{Ethics approval and consent to participate}

The Ethical Committee of Faculty of Medicine, Universitas Gadjah Mada/ Dr. Sardjito Hospital gave approval for this study (KE/FK/0699/EC). Written informed consent was obtained from all parents for participating in this study.

\section{Consent to publish}

Not applicable.

\section{Competing interests}

The authors declare no potential conflicts of interest with respect to the research, authorship, and/or publication of this article.

\section{Author details}

${ }^{1}$ Division of Urology, Department of Surgery, Faculty of Medicine, Public Health and Nursing, Universitas Gadjah Mada/Dr. Sardjito Hospital, Jl. Kesehatan No.1, Yogyakarta 55281, Indonesia. ${ }^{2}$ Pediatric Surgery Division, Department of Surgery, Faculty of Medicine, Public Health and Nursing, Universitas Gadjah Mada/Dr. Sardjito Hospital, Yogyakarta, Indonesia. ${ }^{3}$ Department of Anatomy, Faculty of Medicine, Public Health and Nursing, Universitas Gadjah Mada, Yogyakarta, Indonesia. ${ }^{4}$ Division of Plastic, Aesthetic and Reconstructive Surgery, Department of Surgery, Faculty of Medicine,Public Health and Nursing, Universitas Gadjah Mada/Dr. Sardjito Hospital, Yogyakarta, Indonesia.

Received: 21 June 2020 Accepted: 20 November 2020

Published online: 01 December 2020

\section{References}

1. Marjan Waterloos PH, Spinoit A-F. Hypospadias variants Congenital anomalies of the penis. Berlin: Springer; 2017.

2. Camoglio FS, Zambaldo S, Bruno C, Zampieri N. Hypospadias anatomy: elastosonographic evaluation of the normal and hypospadic Penis. J
Pediatr Urol [Internet]. 2016; Available from: http://dx.doi.org/https://doi. org/10.1016/j.jpurol.2016.02.007

3. Van Der PSCJ. Hypospadias and associated penile anomalies : a histopathological study and a reconstruction of the pathogenesis. J Plast Reconstr Aesthetic Surg. 2007;60:48-60.

4. Spinoit A, Van PC, Groen L, Van LE, Praet M, Hoebeke P. Congenital penile pathology is associated with abnormal development of the dartos muscle: a prospective study of primary penie surgery at a tertiary referra center. J Urol [Internet]. 2015;193(5):1620-4.

5. Sampaio FJB. Collagen and elastic fibers in the penis of human fetuses at 28 weeks postconception. Eur Urol. 1999;970(36):158-63.

6. Hayashi Y, Mizuno K, Kojima Y, Moritoki Y, Nishio H, Kato T, et al. Clinical investigation characterization of the urethral plate and the underlying tissue defined by expression of collagen subtypes and microarchitecture in hypospadias. Int J Urol [Internet]. 2011;18:317-22.

7. Lodish H, Berk A, Zipursky S, Al. E. Collagen: The fibrous proteins of the matrix. In: Molecular cell biology [Internet]. 4th ed. New York: W.H.Freeman; 2000. https://www.ncbi.nlm.nih.gov/books/NBK21582/

8. Theocharis AD, Skandalis SS, Gialeli C, Karamanos NK. Extracellular matrix structure. Adv Drug Deliv Rev [Internet]. 2016;97:4-27.

9. Atmoko W, Shalmont G, Situmorang GR, Wahyudi I, Tanurahardja B, Rodjani A. Abnormal dartos fascia in buried penis and hypospadias: evidence from histopathology. J Pediatr Urol [Internet]. 2018;14(6):536.e1-536.e7.

10. Schnoor M, Cullen P, Lorkowski J, Stolle K, Robenek H, Troyer D, et al. Production of type $\mathrm{VI}$ collagen by human macrophages: a new dimension in macrophage functional heterogeneity. J Immunol. 2008;180(8):5707-19.

11. Liu ZH, Huo JL, Wu ZG, Sun Z, Bai F, Samartzis D, et al. RASSF7 expression and its regulatory roles on apoptosis in human intervertebral disc degeneration. Int J Clin Exp Pathol. 2015;8(12):16097-103.

12. Snodgrass W, Patterson K, Plaire JC, Grady R, Mitchell ME. Histology of the urethral plate: implications for hypospadias repair. J Urol. 2000;164:988-9.

13. Erol A, Baskin L, Li Y, Liu W. Anatomical studies of the urethral plate: why preservation of the urethral plate is important in hypospadias repair. BJU Int. Nove;2000(85):728-34.

14. Henriksen K, Karsdal MA. Type I collagen. Biochemistry of collagens, laminins and elastin structure, function and biomarkers. Berlin: . Springer; 2016.

15. Sun S, Karsdal MA. Type VI collagen. Biochemistry of collagens, laminins and elastin structure, function and biomarkers. Berlin: . Springer; 2016.

16. Karsdal MA. Introduction. Biochemistry of collagens, laminins and elastin structure, function and biomarkers. Berlin: . Springer; 2016.

17. Montag S, Palmer LS. Abnormalities of penile curvature: chordee and penile torsion. Sci World J. 2011;11:1470-8.

18. Abbas TO, Mahdi E, Hasan A, AlAnsari A, Pennisi CP. Current status of tissue engineering in the management of severe hypospadias. Front Pediatr. 2018:5:283

19. Azmy AF. Chordee (Penile Curvature). Hypospadias surgery an ilustrated guide. Berlin: . Springer; 2004. p. 117.

20. Moscardi PRM, Gosalbez R, Castellan MA. Management of High-Grade Penile Curvature Associated with Hypospadias in Children. Front Pediatr. 2017;5(189):1-8.

\section{Publisher's Note}

Springer Nature remains neutral with regard to jurisdictional claims in published maps and institutional affiliations. 